\title{
On Comparison of Two-Level and Global Optimization Schemes for Layout Design of Storage Ponds
}

Wei Lu${ }^{1}$, Xiaosheng Qin ${ }^{1,2 *}$ and Jianjun $\mathrm{Yu}^{3}$

${ }^{1}$ School of Civil and Environmental Engineering, Nanyang Technological University, 50

Nanyang Avenue, Singapore 639798

${ }^{2}$ Environmental Process Modelling Centre (EPMC), Nanyang Environment and Water Research Institute (NEWRI), Nanyang Technological University, 1 Cleantech Loop, Singapore 637141

${ }^{3}$ Environmental Change Institute, School of Geography and the Environment, University of Oxford, Dyson Perrins Building, South Parks Road, Oxford OX1 3QY, UK.

*Corresponding author: Dr. Qin Xiaosheng, School of Civil and Environmental Engineering, Nanyang Technological University, 50 Nanyang Avenue, Singapore 639798; Tel: +6567905288; Fax: +65-67921650; E-mail: xsqin@ntu.edu.sg 


\begin{abstract}
Optimization techniques have emerged as robust tools to aid the planning and design of urban drainage facilities in cost-effective ways. Such an effort was traditionally aided by heuristic methods (like genetic algorithm), which was generally time-consuming and also challenging in reaching convergence for large-scale problems with wide decision spaces. This study proposed a novel optimization method, denoted as two-level optimization (TO) scheme, for supporting rainwater storage pond design in an urban drainage system. Polynomial regression models were established as surrogate models to facilitate the solution of the optimization framework using traditional iteration algorithm. The TO scheme firstly sought the optimal layout of storage ponds on tributary sub-watersheds, and then proceeded to that of the mainstream one to yield the final solution. Through a case study, the TO scheme was compared with the traditional global optimization (GO) scheme where the physical simulation model was dynamically linked with genetic algorithm (GA) to seek the global optimal solution. The performance of two schemes under different constraint settings was analyzed. Effects of related issues such as start-point selection and mainstream design on tributary sub-watersheds were also discussed. The results showed that the proposed TO scheme is a prominent alternative to the traditional GO scheme to support urban water managers for a more science-based decision making towards storage pond implementation in large-scale practical problems.
\end{abstract}

Key words: Urban drainage system; Storage pond; Two-level optimization; Regression; Surrogate; Genetic Algorithm 


\section{INTRODUCTION}

2 Urbanization has been taking place worldwide since the 1950s, resulting in rapid change of city

3 geography and increasing runoff discharges (Wang et al., 2017; Cimorelli et al., 2015). Climate

4 change is also believed to have resulted in escalated frequency and severity of extreme rainfalls

5 around the world (Chen et al., 2016; Kirshen et al., 2014). Both effects are threatening the

6 existing urban drainage systems by posing higher flooding risks and bringing severe damages to

7 property assets, transportation systems, industrial manufacturers, and human lives (Lu et al.,

8 2017a). As one of the efficient solutions to reduce peak flows and cope with flood impact,

9 hydraulic structures such as storage tanks, floodplain storages and stormwater capture tanks are

10 widely adopted (Chapman and Horner, 2010; De Martino et al., 2012; De Paola and Ranucci,

11 2012; De Paola et al., 2013; Tao et al., 2014; Huang et al., 2015; Li et al., 2015; Topa et al.,

12 2015; Bellu et al., 2016). Since implementation of these facilities generally involves significant

From the previous studies, one of the popular methods was to dynamically link a simulation model with an optimization framework that targeted at a specific design of drainage network or layout (Cibin and Chaubey, 2015; Kalcic et al., 2014; Tao et al., 2014). Hydrological simulation models such as storm water management model (SWMM) (Rossman, 2010) and PCSWMM (Lu et al, 2017b) could be utilized for describing the relationship between control measures and hydrological responses. It is also found from previous studies that choosing efficient optimization algorithm is critical for achieving effective convergence of solutions (Cibin and 
Chaubey, 2015). Evolutionary optimization algorithms such as Simulated Annealing (SA), Genetic Algorithms (GA) (Holland, 1992) and NSGA-II (Deb et al. 2002) are popular choices among many optimal designs of storage facilities (Tao et al.,2014; Oxley and Mays, 2014; Li et al., 2015; Cimorelli et al., 2015; Cunha et al., 2016; Yu et al., 2017).

Nevertheless, GA and its peer algorithms still have problems in global convergence and high computational cost if the optimization problem is of a large scale and involves significant number of decision variables (Andre et al., 2001; Lin and Lee, 2004; Kadaba and Nigard, 2014). To tackle such an issue, several multi-level optimization approaches were proposed for splitting massive and complex problems into smaller ones. For example, James and Dovit (1985) proposed a method for decomposing an optimization problem into several sub-problems, and introduced a coordination mechanism that preserved coupling between sub-problems. The method was tested for an assembled structural optimization problem where a shorter design time was achieved. Cibin and Chaubey (2015) developed a multi-level spatial optimization approach (MLSOPT) for dealing with watershed-scale spatial optimization problems by disaggregating the watershed into sub-watersheds and identifying optimum layout for each one. The study demonstrated that MLSOPT achieved robust convergence and high-efficiency in computation compared with the single-level option. Wang et al. (2017) presented a two-stage multi-objective optimization scheme for designing storage tanks. The scheme included an analytical module (stage I, to obtain a preliminary scheme) and an iteration module (stage II, to search for optimal scheme based on the preliminary scheme). Generally, few of these studies took into account the hydrological characteristics of an urban watershed in dividing sub-watersheds, and carried out optimization in consideration of tributary and mainstream interactions. 
48 Moreover, building and calibrating a large-scale hydrological model is normally time-consuming

49 (Krebs et al., 2013), and the high computational burden of tautologically running the simulation50 aided optimization models may restrict the applicability of the method (Lu et al., 2017a). One

51 possible solution is to use surrogate models like artificial neural network (Sreekanth and Datta,

52 2011), moving least squares (Yu et al., 2015b) and response surface models (Seo et al., 2012), to

53 replace the physical models, instead of linking them directly into the optimization modules.

54 These surrogate models could be built up with multiple scenarios simulated from hydrological

55 models, and applied to approximate the input-output hydrological relations for achieving computationally more efficient predictions (Yu et al., 2015a). Previously, rare studies were

57 reported in adopting surrogate models in multi-level optimization frameworks in the field of drainage infrastructure design.

Therefore, this study aims to propose a new optimization scheme for supporting optimal design of storage ponds by embedding surrogate models into a two-level optimization framework. The

62 level-I optimization will focus on upstream area, mainly involving tributary sub-watersheds. Upon receiving the outputs from the level-I, the level-II optimization will embark on

64 downstream area comprising the mainstream sub-watershed. Quadratic regression models (i.e. the surrogate models) are introduced to describe the hydraulic relationships between the layout

66 (i.e., location and sizes) of storage ponds and the overloaded flood volume in the drainage

67 system. The proposed scheme will be compared with traditional single-level optimization scheme in terms of applicability, reliability and computational efficiency. A hypothetical urban

69 watershed is introduced as the study case and discussed on comparing the two schemes. 


\section{METHODOLOGY}

72 Figure 1 shows a flowchart of the overall methodology. Two optimization schemes for layout

73 design of storage ponds are introduced, including (i) a two-level optimization (TO) scheme with

74 quadratic regression and gradient-based solution algorithm; (ii) a global optimization (GO)

75 scheme with genetic algorithm aided solution. Details of the two schemes are given below.

76

77 Place Figure 1 here

78

79

80

2.1 TO scheme

81 Establishment of the physical model

82 A physical model is normally utilized to demonstrate the hydraulic or hydrologic relations in an urban drainage system. SWMM is a dynamic model for linking rainfall to runoff in the drainage

84 networks and tracking the water quality of runoff generated within each sub-watershed (Aad et

85 al., 2009), and it has been used worldwide for planning, design and analysis related to urban

86 drainage systems (US EPA, 2017). Generally, mainstream and tributaries can be identified

87 according to the hydraulic structure of a drainage system. The criteria of division could be based

88 on considerations of (i) computational efficiency (i.e., no excessive number of sub-watersheds)

89 and (ii) local hydrological and topographical condition of the study case (i.e., runoff from each

90 sub-watershed independently flows into the mainstream sub-watershed). Similar criteria of sub-

91 watershed definition could be applied to many other urban areas; however, from practical point

92 of view, the decision-makers or stake holders may also get involved in the discussion of 
division of urban watershed for a better consideration of local conditions. In this study, subwatersheds contributing to tributaries will be grouped into tributary sub-watersheds, whereas those contributing to the mainstream will be categorized as mainstream sub-watersheds. In TO scheme, the tributary sub-watersheds are the target areas for level-I optimization, and the mainstream sub-watershed will be tackled at level-II.

\section{Establishment and validation of surrogate models}

Polynomial surrogate models are adopted to explore the relationships between several explanatory variables (e.g., locations and size of interested hydraulic units) and one or more response variables (e.g., performance and construction cost of these hydraulic units). Polynomial models are essential intermediaries for replacing the physical models during the optimization process in TO scheme. The main reason lies on the avoidance of using simulation model under an optimization framework, which may bring along technical difficulty and high computational burden. Also, comparing with other surrogate models like artificial neural network (ANN), polynomial models have explicit mathematical expressions which are more favorable for optimization model expression and solution. Taking quadratic models as an example, the formulation can be written as (Lucas, 1976):

$$
y=b_{0}+\sum_{q=1}^{s} b_{q} x_{q}+\sum_{q=1}^{s} b_{q q} x_{q}^{2}+\sum_{1 \leq q<r \leq s} b_{q r} x_{q} x_{r}+e
$$

where $y$ is the response or dependent variable; $x_{q}(q=1,2, \ldots, s)$ are the independent experimental variables; $b_{0}, b_{q}, b_{q q}$ and $b_{q r}(q=1,2, \ldots, s ; r=1,2, \ldots, s)$ are parameters to be estimated using the data from experiment, and $e$ is an error term; $q$ and $r$ are indexes for $x$ and $b$, and $s$ denotes the total number of variables $x$. 
For model establishment, all the junctions over the study area are assumed potential locations to install storage ponds. Random samples of storage pond layout (i.e. locations and surface area of ponds) can be generated by using Latin Hypercube Sampling (LHS) (McKay et al., 1979). For each sample of layout, SWMM model will run under a specific design rainfall to compute the total surcharged runoff (i.e., flood volume) from all nodes (i.e., junctions and ponds) within subwatersheds. Then a polynomial surrogate model is introduced to mimic the relationship between the layout of storage ponds and the corresponding flood volume. For model validation, the samples can be split into training and testing groups. The testing group does not contribute to the model construction, but only be used to test the predicted values from the training group.

\section{Formulation of optimization models}

In this study, the total number of implemented storage ponds within each sub-watershed is firstly determined. The criteria could be set by the decision makers considering budget availability, land susceptibility, or flood control balance. Here we use the evenness of flood distribution over subwatersheds under the design rainfall. After the number of storage ponds are determined, the optimal layout (including location and size) of ponds within each sub-watershed can be identified through the following two-level optimization process. In level-I optimization, the model will generate the optimal layout of storage ponds in each tributary sub-watershed. By controlling the total flood volume in the tributary area, it lays a foundation for the level-II optimization, which focuses on the mainstream area. Let $i$ denote the $i^{\text {th }}$ sub-watershed $\left(S_{i}\right)$, the corresponding optimization model can be formulated as (Tao et al. 2014):

$$
\operatorname{MinTC}_{i}=\sum_{k=1}^{j_{i}}\left[a \cdot\left(A_{k} \cdot H_{k}\right)^{e}+b \cdot A_{k}+g\left(A_{k}\right)\right]
$$

subject to 
(2c)

$$
a, b, g(\cdot)=\left\{\begin{array}{c}
\text { const, } A_{k} \geq A_{\text {min }} \\
0, A_{k}<A_{\text {min }}
\end{array}, \forall k\right.
$$

$$
A_{\text {min }} \leq A_{k} \leq A_{\max }
$$

where $T C_{i}$ stands for the total cost of building the storage ponds in $S_{i} ; j_{i}$ denotes the number of storage ponds in $S_{i} ; p_{i}$ is the maximum number of storage ponds in $S_{i} ; k$ is the index of $j_{i}(k=1$, $\left.2, \ldots, j_{i}\right) ; A_{k}$ denotes the surface area of the $k^{\text {th }}$ storage pond, varying within the range of $\left(A_{\min }\right.$, $\left.A_{\max }\right) ; H_{k}$ denotes the depth of the $k^{\text {th }}$ storage pond; $a$ and $e$ are coefficients pertaining to the dimension of storage pond and $b$ is a coefficient reflecting the unit land cost in the area; $g(\cdot)$ is the launching cost of each storage pond (Li et al., 2015; Huang et al., 2015), which can also be considered as an additional cost for initializing the storage pond construction. Eq.2d denotes that $a, b$ and $g(\cdot)$ will automatically turn to 0 for leaving out the construction cost of a specific storage pond when the iterated input of $A_{k}$ is less than $A_{\text {min }}$; otherwise, they will be set constant, regardless of the exact size of the storage pond. $F_{i}$ denotes the total flood volume from all junctions (or ponds) in $S_{i}$, which is equal to the excessive runoff that beyond the capacity of junctions and storage ponds in $S_{i} . F_{i}$ is calculated based on the corresponding variables $A_{k}$ of the regression model (here denoted as function $f_{i}$ ) for $S_{i}$; $c_{i}$ is defined as the total flood volume threshold from all junctions (or ponds) in $S_{i}$. 
161 The mainstream sub-watershed is distinguished from the rest sub-watersheds located in

162 tributaries, as the hydraulic-hydrological performance of the mainstream drainage is significantly

163 influenced by the runoff from tributaries. Thus, level-II optimization will adopt the optimization

164 results from level-I (i.e., layout of storage ponds in all the tributary sub-watersheds) as its inputs.

165 The corresponding regression model will be established for the mainstream sub-watershed,

166 keeping all tributary watersheds fixed at $A_{k}\left(k=1,2, \ldots, j_{i} ; i=1,2, \ldots\right)$ from level-I. The

167 objective of level-II optimization is the optimal layout of storage pond in mainstream sub-

168 watershed. The optimization formulation at level-II is formulated as:

169

$$
\operatorname{MinTC}_{M}=\sum_{m=1}^{j_{M}}\left[a \cdot\left(A_{m} \cdot H_{m}\right)^{e}+b \cdot A_{m}+g\left(A_{m}\right)\right]
$$

170 subject to

171

172

173

174

(3c)

175

176

(3d)

177

178

$$
F_{M}=f_{M}\left(A_{m}\right) \leq c_{M}, \forall m
$$

$$
j_{M} \leq p_{M}
$$

75

$$
a, b, g(\cdot)=\left\{\begin{array}{c}
\text { const, } A_{m} \geq A_{\min } \\
0, A_{m}<A_{\text {min }}
\end{array}, \forall m\right.
$$

180

where $T C_{M}$ stands for the total cost of building the storage ponds in mainstream; $j_{M}$ denotes the 
182 number of storage ponds in mainstream; $p_{M}$ is the maximum number of storage ponds in 183 mainstream; $m$ is the index of $j_{M}\left(m=1,2, \ldots, j_{M}\right) ; A_{m}$ denotes the surface area of the $m^{\text {th }}$ storage 184 pond; $H_{m}$ denotes the depth of the $\mathrm{m}^{\text {th }}$ storage pond; $a, e, b$ and $g(\cdot)$ are similar coefficients from 185 level-I. $F_{M}$ denotes the total flood volume from all junctions (or ponds) in mainstream, which is 186 calculated based on the corresponding regression model (here denoted as function $f_{M}$ ); $c_{M}$ is defined 187 as the total flood volume threshold from all junctions (or ponds) in mainstream. In addition, Eq. 188 3f emphasizes that the areas and locations of storage ponds outside the mainstream sub-watershed 189 are kept unchanged in the level-II optimization process.

190

\subsection{GO scheme}

192 The GO scheme searches optimal solutions at a global scale. Compared with TO scheme, the GO one does not need division of sub-watersheds, and the number of storage ponds is unconstrained

194 in the study area. GA is adopted for searching solutions that could minimize the construction cost 195 and satisfy local constraints (e.g., total flood volume, area limit of storage ponds, etc.). As the problem involves much more decision variables when compared with TO scheme, the sampling

197 space in GA has been largely expanded. The optimization formulation is shown as:

$$
\operatorname{MinTC}_{N}=\sum_{n=1}^{N}\left[a \cdot\left(A_{n} \cdot H_{n}\right)^{e}+b \cdot A_{n}+g\left(A_{n}\right)\right]
$$

199 subject to

$$
F_{N}=s\left(A_{n}\right) \leq c_{N}, \forall n
$$

201

(4b)

$$
a, b, g(\cdot)=\left\{\begin{array}{c}
\text { const, } A_{n} \geq A_{\text {min }} \\
0, A_{n}<A_{\text {min }}
\end{array}, \forall n\right.
$$




$$
A_{\min } \leq A_{n} \leq A_{\max }
$$

206

207

208

209

210

211

212

213

214

215

216

217

218

219

220

221 222 Singapore, 2017).

223

224

225 Place Figure 2 here

226

\section{CASE STUDY}

where $T C_{N}$ and $N$ stands for the total cost of building the storage ponds and total number of storage ponds in the entire study area, respectively; $n$ is the index of $N$; $F_{N}$ denotes the total flood volume from all the overloaded junctions and ponds, which is calculated based on the output of SWMM model (s) under different scenarios of $A_{n} ; c_{N}$ is defined as the total flood volume threshold in the study area. Definitions and principles of the rest variables and constants remain the same as in the TO scheme.

\subsection{Case Background and Model Setup}

Description of the study site

A hypothetical urban catchment adapted from a real tropical urban area is selected for demonstrating the proposed design framework. Figure 2 shows the general map and layout of the existing drainage network of the study site. The site is characterized by urban commercial and residential areas under a tropical climate, where the average rainy days is about 167 days of the year and the maximum hourly rainfalls could reach up to $147 \mathrm{~mm}$ (Meteorological Service 


\section{Design rainfall}

229 Rainfall are designed based on intensity-duration-frequency (IDF) curves and Huff distribution.

230 IDF curves reveal the characteristics of the rainfall extremes, which are established based on

231 annual maximum rainfalls with various durations (Arnbjerg-Nielsen, 2012). Huff storm

232 distribution includes four types of rainfall patterns, with peak intensity occurring in different

233 quarters of the duration in each pattern (Chow et al., 1988). This study assumes a design rainfall

234 (with total depth at $107.5 \mathrm{~mm}$ ) with 1-hour duration, Type-II Huff distribution and 25-years

235 return period (PUB, 2011). Then the design rainfall is established to set up the model and

236 generate flood scenarios. Figure 3 shows the corresponding hyetograph with an interval of 5

237 minutes.

240 Place Figure 3 here

241

242

SWMM model setup and division of sub-watersheds

244 An urban drainage model based on SWMM is established for the study case with an area of

$24525.14 \mathrm{~km}^{2}$. In this study, the dynamic routing model is adopted in SWMM; it solves the complete

246 one-dimensional Saint-Venant flow equations and therefore produces the most theoretically

247 accurate results. Dynamic wave routing can address issues related to channel storage, backwater,

248 flow reversal and pressurized flow, and it is suitable for systems subjected to significant

249 backwater effects due to downstream flow restrictions (e.g. the effect of downstream pond

250 design on flooding of upstream areas) (Rossman, 2010). Originally, the model consists of 44 
251 subcatchments, 81 junctions, 81 conduits and 1 outfall. These subcatchments are basic

252 hydrological units in SWMM, and they are grouped into several sub-watersheds. Depending on

253 the criteria of division, the drainage system will be aggregated into 1 mainstream sub-watershed

254 and 3-6 tributary sub-watersheds. Based on this structure, 34 subcatchments are considered as in

255 tributary areas, and the remaining 10 subcatchments contribute their runoff directly to the

256 mainstream. The 34 subcatchments in tributary areas are disaggregated into three sub-watersheds

257 (S1, S2 and S3), which have 11, 12 and 11 subcatchments (20, 21 and 20 junctions), respectively.

258 The rest subcatchments form the mainstream sub-watershed S4, which has 10 subcatchment (20

259 junctions). Figure 4 shows the result of sub-watershed division based on the criteria mentioned in

260 the methodology section. For convenience in identifying pond locations, the potential storage

261 ponds are indexed (denoted as Pond Index) based on the junction indexes as shown in Figure 2.

262

263

264 Place Figure 4 here

265

266

267 Setup of optimization framework

268 In TO scheme, the Constrained Nonlinear Minimization Solver (CNMS) (Coleman et al., 1999;

269 Matlab, 2015) is adopted as the iterative algorithm for searching the optimal layout in TO

270 scheme, and the CNMS is embedded with the regression model as one of model constraints (see

271 Eq.2c and Eq.3c). In GO scheme, the SWMM model is directly linked with MATLAB platform.

272 Therefore, the execution results of SWMM model can be automatically extracted into MATLAB

273 for the iteration process of GA. Also, a penalty-based algorithm is adopted in GA process for

274 model solution. 
276 To test the TO scheme, the following parameter settings are adopted (as Scenario I).

277 The coefficients of $a, b$ and $e$ are set as: $a=\$ 500, b=\$ 100$, and $e=0.69$. As the launching cost

278 for each storage pond, the value of $g(\cdot)$ is assumed to be $\$ 5000$ if the pond is actually

279 implemented. The minimum and maximum areas for each storage pond are set as $A_{\min }=500$ and

$280 A_{\max }=10000 \mathrm{~m}^{2}$, respectively. The depth of each storage pond is set to be equal to its original

281 junction for ease of construction. If the iterated input of $A_{k}$ and $A_{m}$ in TO is less than $500 \mathrm{~m}^{2}$, it

282 will not be implemented and there is no construction cost calculated for that pond. For the TO

283 scheme, the total flood volume threshold for all nodes in each sub-watershed $\left(C_{i}\right.$ and $\left.c_{M}\right)$ is set to

$28420,000 \mathrm{~m}^{3}$. For consistency, the $c_{N}$ is set at $80,000 \mathrm{~m}^{3}$ for the four sub-watersheds in GO scheme.

286 For the TO scheme under Scenario I, the maximum number of storage ponds is set to 42. In

287 practical applications, this number could be determined based on financial capability, available

288 land area for pond installation, and policy requirement. Then, the number of implemented

289 storage ponds $p_{i}$ within sub-watershed $S_{i}$ can be determined either by decision-makers’

290 preference or local condition. In this study, we use design rainfall to test the flooding condition

291 for all sub-watersheds and then apply the percentage of flood volume at each sub-watershed to

292 estimate the maximum number of ponds that should be deployed into each sub-watershed. The

293 detailed results are shown in Table 1 ( $p_{2}$ is set as 10 , because $S_{2}$ originally has more junctions

294 than other sub-watersheds).

297 Place Table 1 here 
Setup of surrogate models

301 The quadratic regression models are adopted and established in TO scheme. Eq.1 gives the

302 formulation of the models. The sampling number for each sub-watershed is customized to 1000.

303 To ensure the accuracy of quadratic models, 90\% of the samples (i.e., 900 sample sets) and their

304 outputs are used for model establishment, while the rest $10 \%$ are used for verification. The

305 testing results for three tributary sub-watersheds S1, S2 and S3 are shown in Figure 5 (sub-

306 figures 5a, 5b and 5c correspond to S1, S2 and S3, respectively). In Figure 5, each scatter

307 represents a sample, plotted by using the predicted value of total flood volume from quadratic

308 model on the $x$ axis and simulated results from testing group on the $y$ axis. The straight line in

309 each sub-figure represents the line ' $y=x$ '. From Figure 5, it is clear that most of the regressions

310 achieved a decent fitness with $\mathrm{R}^{2}$ above 0.95 , except for sub-watershed $S 2$ which has a $\mathrm{R}^{2}$ of

311 0.89. This is mainly because of the over-estimation of the flood condition in a small portion of

312 samples by the regression model. After verifying the accuracy of quadratic models, the optimal

313 layout of sub-watersheds $S 1$ to S3 is identified by running level-I of TO optimization (details are

314 provided in the Result Analysis and Discussion). Afterwards, the quadratic regression model is

315 built for the mainstream sub-watershed $S 4$ (see Figure $5 \mathrm{~d}$ ) and the $\mathrm{R}^{2}$ level of regression

316 performance is 0.977 . The detailed coefficients of quadratic models can be referred to the

317 Supplementary Materials.

318

319

320

Place Figure 5 here

321

322 
323

324

325

326

327

328

329

330

331

332

\subsection{Result Analysis and Discussion}

\section{Results of TO and GO scheme}

To investigate the two optimization schemes under different settings of constraints, two more scenarios, denoted as Scenarios II and III, are added in addition to Scenario I. Scenario II assumes a lower maximum number of storage ponds (i.e. 38), and a higher threshold of flood volume for each sub-watershed (i.e. $30,000 \mathrm{~m}^{3}$ ). The maximum storage pond area is limited to $8,000 \mathrm{~m}^{2}$. Scenario III allows more storage ponds to be constructed (maximum number set to 50) but their maximum storage area is reduced to $6,000 \mathrm{~m}^{2}$. The threshold of flood volume for this scenario is set to $15,000 \mathrm{~m}^{3}$. There are no strict rules to set these parameters, as the main purpose is to test the consistency of TO performance under different conditions. Since the maximum number of ponds has changed, the allocation patterns are also adjusted. Under Scenario III, the number of ponds is still allocated based on the same percentage of flooding used under Scenario I. The allocation pattern for Scenario II has some adjustment assuming decision-makers prefer to add more storage ponds in the mainstream sub-watershed. Scenario IA is added to test the effect of changing the maximum number of ponds for the TO scheme under Scenario I. For a fair comparison between TO and GO schemes, Scenario IA adopts the same settings as Scenario I, except that the maximum number of storage ponds is fixed at 71 which is the same as the optimal number of ponds obtained from GO scheme under Scenario I. Scenario IB is another scenario with different sub-watershed division scheme and it will be elaborated later.

Table 2 shows the optimal layouts of storage ponds for all sub-watersheds and the overall performance of TO scheme under Scenario I. Generally, for the TO scheme, the solution with a layout of 42 storage ponds could be obtained, with an overall cost around \$42.41 million and 
overall flood volume at 78,418 $\mathrm{m}^{3}$. For the GO scheme, after a 50-generation iteration (with a population size of 200 for each generation) in the GA-SWMM interaction process, the solution with a layout of 71 storage ponds among 81 potential locations is found (details can be referred to Supplementary Material); the corresponding overall cost is $\$ 48.09$ million and the overall flood volume is $79,934 \mathrm{~m}^{3}$. The cost of GO scheme is about $13.4 \%$ higher than that of TO scheme, while the simulated flood volume under both schemes are both close to the sum of thresholds for all sub-watersheds (i.e. $80,000 \mathrm{~m}^{3}$ ).

Place Tables 2 here

Table 3 summarizes the results of the two optimization schemes under Scenarios I, IA, II and III. Generally, both schemes would lead to similar flood levels, and the TO scheme would achieve a lower cost under Scenarios I, II and III (reduction of cost varied from $8.7 \%$ to $11.8 \%$ ) due to reduced number of storage ponds while satisfying local criteria of flood reduction. Whereas, the Scenario IA for TO scheme achieved a final layout of 49 ponds and the overall cost would be somewhat higher than that with TO scheme in Scenario I due to the heavy investment in mainstream sub-watershed (which has a layout of 17 storage ponds at a cost of $\$ 23.21$ million based on its level-II optimization). This means that, in Scenario IA, the ponds in the mainstream area are suggested to accommodate higher runoff and demand a higher cost of construction. This also explains the increase of total cost for this scenario compared with Scenario I. The cost from TO scheme under Scenario IA is slightly higher than that from GO scheme, possibly due to the fact that GO's searching is more global, and could obtain solutions with lower average area of 
370 ponds (i.e. $3282 \mathrm{~m}^{2}$ ) than TO scheme under Scenario IA (i.e. $5905 \mathrm{~m}^{2}$ ). The above results

371 demonstrate that, in terms of optimization performance, TO scheme could lead to solutions with

372 superior or at least comparable results than GO scheme. For detailed optimization results, readers

373 can refer to Supplementary Material.

374

375 In terms of efficiency of model runs, the total run times for the TO and GO schemes are

376 approximately 3.3 and 6.5 hours, based on a desktop computer (Xeon ${ }^{\mathrm{TM}}$ W3550 CPU @3.07

377 GHz, 12G RAM). The run time for the TO scheme is estimated based on the following

378 considerations: (1) each SWMM run is about 3s and the time required to run all 1000 samples for

3794 sub-watersheds is about $3 \mathrm{~s} \times 4 \times 1000 / 3600=3.3$ hours; (2) the optimization process generally

380 takes less than 1 minutes to complete. For GO scheme, the simulation model is called within the

381 optimization framework multiple times depending on the population size for each generation and

382 the total number of generations. It is worth mentioning that the workload of the sampling process

383 to set up the regression surrogate model could be easily alleviated by using parallel computing

384 (e.g. multiple computers, multiple CPU cores, or cloud computing). It is technically more

385 challenging to reduce computational time for the GO scheme.

386

387

388 Place Table 3 here

389

390

\section{Impact of selecting different start points on optimization results}

392 Based on model test, the start points (SP) (i.e., initial value of variables, which refer to the areas

393 of ponds) was found to have a noticeable effect on the optimization results. Figure 6 shows the 
394 testing results for 5 runs with different SPs for Scenario III. Figures 6a shows the solutions of 395 storage pond layout and their corresponding objective function values (i.e. construction costs) of

3965 runs for sub-watersheds S1 to S4. Each sub-watershed adopts 5 random sets of SPs generated

397 by LHS. It is found that the majority of storage ponds have stable areas among five runs. From

398 the upper right of Figure 6a, the objective function values (i.e. construction cost) of 5 runs for 4

399 sub-watersheds show somewhat fluctuations, especially for sub-watersheds S3 under Run 4

400 ( 12.1\% lower than average) and S2 under Run 5 ( 14.6\% higher than average), respectively.

401 The performance of TO scheme is generally stable towards different SPs. For TO scheme, the

402 solutions of optimization models show a strong dependence on SP; some sets of SPs cannot even

403 support a feasible solution (i.e., they cannot satisfy the constraints before reaching the stopping

404 criteria) and reselection of different SPs may be necessary. Such an infeasibility issue is caused

405 by the inherent error associated with the quadratic regression model and the limitation of solution

406 algorithm (i.e. CNMS) that is affected by the selection of SPs and local optima.

407

408 For GO scheme, Figure 6b shows that the overall cost (i.e. GA fitness values) would range from

40949.8 to 55.6 million, which is comparable to the 48.1 million achieved by TO scheme under the

410 same scenario. Moreover, Figure 6b demonstrates that the optimized layout from GO is highly

411 diversified among various runs; while the final solutions in the TO scheme are much more stable

412 (as shown in Figure 6a). Apparently, when the scale of the problem is large (like the studied

413 case), GA may not perform satisfactorily in seeking global optimal solutions.

414

415

416 Place Figure 6 here

417 


\section{Effect of mainstream pond design on sub-watershed flooding}

420 During the sampling stage for building up the quadratic regression model, the physical model

421 (SWMM) would have to run based on each sample input. The physical model takes the entire

422 watershed into consideration, including the interactions between the mainstream and tributary

423 sub-watersheds. It is found that the layout of storage ponds in the mainstream sub-watershed

424 would also cause flood conditions in the tributary sub-watersheds, mainly through the connecting

425 junctions. To control or alleviate such an effect, if desired, we could consider modify the level-II

426 optimization model structure. For example, we could add additional constraints of limiting the

427 flood volume at the junctions of concern (e.g. sensitive areas like residential buildings, main

428 roads, and commercial centers) within a certain range. For demonstration purpose in this study, if

429 the refluence of excessive runoff from the mainstream junctions to the adjacent tributary

430 junctions (defined as the "backflow effect") is of the major concern to decision makers, three

431 extra constraints (denoted as Extra-con) could be added into the level-II optimization framework

432 to control the gap between the flood volume of the adjacent junctions in the mainstream model

433 and that in the tributary model within an allowable level (i.e. $500 \mathrm{~m}^{3}$ ). Examples of adjacent

434 tributary junctions are J09, J21, and J63, as shown in Figure 2. Specifically, from ordinary

435 condition of node flooding under Scenario I, the flood volume for J09, J21 and J63 is 6348, 0

436 and $2400 \mathrm{~m}^{3}$, respectively. Thus, the extra constraints limit the maximum flood volume of J09,

$437 \mathrm{~J} 21$ and J63 below 6848, 500 and $2900 \mathrm{~m}^{3}$, respectively. The way to limit the flood volume of

438 these junctions is to add additional constraints to the optimization model (i.e. Equation 3). These

439 constraints are established using regression models which reflect the relationship between flood

440 volumes of adjacent tributary junctions and area of mainstream ponds. 
442 Figure 7 shows the 1000 sample scenarios of total flood volumes at three tributary sub-

443 watersheds (i.e. S1, S2 and S3) and the mainstream sub-watershed S4, where the $x$ axis denotes

444 the flood volume in the mainstream sub-watershed in an ascending order. It is indicated that the

445 flood volumes from the sampled layouts of storage ponds would vary in both the mainstream

446 sub-watershed and three tributary sub-watersheds. The correlation coefficient of flood volume

447 between the mainstream and the tributary sub-watersheds is found to be 0.765 , indicating a

448 generally positive correlation and possible backflow effect from mainstream to the tributary sub-

449 watersheds. Figure 8 shows the flooded volume at various junctions (with a threshold of $500 \mathrm{~m}^{3}$ )

450 from the two types of models under the TO scheme, which consist of the original model

451 (Scenario I) and the model with Extra-con on controlling backflow effect. It can be found that

452 the junctions of J38 and J63 are heavily flooded in the original model; with the Extra-con, the

453 flooding in J38 and J63 would disappear and other junctions would have somewhat minor

454 fluctuations of flood volume. The details of pond layout can be referred to the Supplementary

455 Materials. The results demonstrated that, for TO scheme, more specific constrains at sensitive

456 junctions could be adopted to mitigate the effect of mainstream pond design on flooding

457 conditions of the sub-watersheds. In terms of the overall flood magnitude and cost, the model

458 with Extra-con would decrease the total flood volume from 78,418 to $68,977 \mathrm{~m}^{3}$ and total cost

459 from \$42.41 to 41.97 million, in comparison to those from the original model under Scenario I.

$462 \quad$ Place Figures 7 and 8 here

463

464 
In this study, the urban watershed is divided into sub-watersheds according to computational

467 efficiency and local hydrological and topographical condition. In order to examine the effect of

468 choosing different division schemes, we have tested another way of dividing the sub-watersheds.

469 Figure 9 shows the new division over the study domain, where there are 11, 8, 16 and 9

470 subcatchments for S1, S2, S3 and S4, respectively. Extra scenario simulations, denoted as

471 Scenario IB, are carried out based on the new division scheme and the relevant results are also

472 summarized in Table 3. The Scenario IB adopts similar settings as Scenario I (e.g. maximum

473 number of total storage ponds and maximum area for each ponds), and also shows similar

474 outputs in terms of overall cost and flooding. This implies that the effect of using different

475 division of sub-watersheds on optimized results is insignificant. The detailed layout of storage 476 pond is summarized in the Supplementary Materials.

477

478

$479 \quad$ Place Figures 9 here

480

481

482 Effect of different GA options on optimized results of GO scheme

483 In GO scheme, besides start points, options of GA parameters (e.g. elite count, crossover fraction

484 and mutation function) may also affect the algorithm's efficiency for searching global optimal

485 solutions and satisfying local constraints. In this study, the GA adopts default values for most of

486 the parameters defined in MATLAB (MATLAB, 2015). For example, the rates for elite count

487 and crossover fraction are set to 10 (twentieth of the Population Size) and 0.8, respectively and 
488 the "adaptive feasible" is chosen as the mutation function, which is the recommended function

489 for constraint-dependent optimization (MATLAB, 2015). To further investigate the sensitivity of

490 GO scheme towards options of GA, three extra GO scheme runs (with different settings on

491 crossover fraction and elite count rate) under Scenario I are carried out, and the results are

492 summarized in Table 4. It is shown that the overall cost would range from $\$ 46.6$ to 49.8 million.

493 Runs No. 2 and No. 4 achieve lower overall costs than that from original GA setting (i.e. No. 3),

494 and their total flood volume is relatively closer to the threshold (i.e. $80000 \mathrm{~m}^{3}$ ). In general, the

495 reliability and convergence of GO scheme under various GA options are acceptable. More

496 detailed information of iterations and final solutions can referred to Supplementary Materials.

497

498

499 Place Table 4 here

500

501

502

\section{Further discussion}

503 This study attempts to integrate various techniques into a TO scheme for storage pond planning

504 and design. These techniques involve urban drainage modeling, sub-watersheds division,

505 surrogate model construction and CNMS iterative algorithm. The performance of the proposed

506 TO scheme is compared with traditional GO scheme. It is revealed that the TO scheme has the

507 following advantages:

508

509 (1) Applicability

510 Applicability indicates the scope of the proposed scheme to be used in applications (Yu et al,

511 2015a). The TO scheme could be applied to optimize a large-scale catchment which involves a 
512 significant number of decision variables. With the aid of the two-level (or even multi-level)

513 optimization structure, the number of variables in each level would significantly decrease;

514 furthermore, within each level, the regression models are combined with an iterative algorithm

515 for more efficient searching of the optimized results. As for GO scheme, it is proven to be

516 difficult or time-consuming in reaching a global optimal solution if the problem involves a large

517 number of decision variables. Also, under various modelling scenarios in this study, it is found

518 that the TO scheme managed to converge to better or comparable results in terms of overall cost

519 compared with GO scheme (see Table 3).

520

521 (2) Reliability

522 Reliability is an indicator showing logical coherence of the scheme and the feasibility of the 523 optimized results under uncertainty. In TO scheme, the regression models are verified (see

524 Figure 5) for carrying on the optimization framework. Uncertainty issues, including setup of start 525 points and mainstream effect, and their impact on optimized results were also investigated.

526 Figure 6 proves a more stable performance of TO scheme over GO scheme.

527

528 (3) Computational efficiency

529 In this study, TO scheme showed a relatively more efficient computational effort than GO

530 scheme. However, TO is deemed potentially more advantages in undertaking a parallel

531 computing using multiple cores or computers, as its main time-consuming part is the running of

532 samples to build up the surrogate models and it needs almost negligible time to run the

533 optimization model. GO scheme requires both physical model and optimization run at the same

534 time, which is more challenging to be parallelized. 
536 As the first attempt in proposing TO scheme, we also encountered some limitations. Firstly, the

537 scale control of each tributary sub-watershed is an important issue. For TO scheme in this study,

538 the decision variables (i.e., number of junctions) for each sub-watershed is controlled around 20,

539 ensuring sufficient accuracy of regression models (e.g., in Figure 5, all the regression models

540 achieved a decent fitness with $\mathrm{R}^{2}$ around 0.9 or above). However, when the number of decision

541 variables increases significantly (e.g. each sub-watershed has over 100 junctions), it is likely that

542 the regression models could not achieve an acceptable level of fitness. By simply increasing the

543 number of sub-watersheds may bring extra run time and may not be applicable for optimizing

544 large-scale watersheds. Multi-level optimization may be a good solution, but it needs further

545 investigations. Secondly, as indicated in Scenarios I and IA, the performance (i.e. overall cost) of

546 TO scheme is subjected to the user-defined settings (e.g. patterns and maximum number of

547 storage ponds), which may bring along uncertainty issues for the optimization results. Users are

548 recommended to set a relatively lower limit of the number of ponds for saving cost, if the

549 constraints of flood volume can be satisfied. Moreover, TO scheme could offer a comparable

550 (may not be necessarily more optimal) solution to GO scheme, with respect to minimization of

551 total system cost and satisfaction of system constraints. But we should bear in mind that the main

552 advantage of TO scheme lies in the saving of much computational efforts when the physical

553 model is large and/or the dynamic linkage of GA and physical model becomes impractically

554 complex. Thirdly, in practical applications, if the number of storage ponds exceeds the capacity

555 of construction at one time, sequence of construction may need to be considered. The sensitivity

556 of flood from partial deployment of storage ponds at different stages could be analyzed in order

557 to prioritize the construction efforts for a better flood control effect. For example, if there is no 
storage ponds for the case in this study, the flood volume for the entire system could reach 693.2 thousand $\mathrm{m}^{3}$. Assume we construct ponds for one sub-watershed at a time based on the model solution for Scenario I, the flood volume would drop to 537.4, 572.2, 537.7 and 509.8 thousand $\mathrm{m}^{3}$ with individual deployment of ponds in $S 1, S 2, S 3$, and $S 4$, respectively. The implementation plan could also be guided by the model with reduced total number of ponds.

\section{CONCLUSIONS}

A two-level optimization (TO) scheme was proposed for supporting optimal design of storage ponds in urban drainage systems. The scheme focused on optimization of storage pond layout in tributary sub-watersheds (level-I optimization) first, and then proceeded to optimization for the mainstream sub-watershed (level-II optimization). The performances of the proposed TO scheme and the traditional global optimization (GO) scheme were tested and compared in terms of applicability, reliability and computational efficiency. A hypothetical case adapted from a tropical urban community was selected for demonstrating the applicability of methodology. The results showed that both schemes could achieve convergences under different settings of optimization constraints. Compared with the GO scheme, the TO one could achieve a comparable or lower system cost, save almost half of the run time and obtain a more stable solution with different setups of start points. It is a good alternative of GO scheme for tackling large-scale problems, although there still much room for improvement in the future. Also, for both schemes, the effect of backflow from mainstream to tributary areas and their propagation to optimization results need to be further investigated. 
584

\section{ACKNOWLEDGEMENT}

The research work was supported by Singapore's Ministry of Education (MOE) AcRF Tier 1 Project (Ref No. RG170/16; WBS No.: 4011766.030).

\section{REFERENCES}

Aad, M. P. A., Suidan, M. T., Shuster, W. D., 2009. Modeling techniques of best management practices: Rain barrels and rain gardens using EPA SWMM-5. J. Hydrol. Eng., 10.1061/(ASCE)HE.1943-5584.0000136.

Andre, J., Siarry, P., Dognon, T., 2001. An improvement of the standard genetic algorithm fighting premature convergence in continuous optimization. Adv. Eng. Software, 32(1), 4960.

Arnbjerg-Nielsen, K., 2012. Quantification of climate change effects on extreme precipitation used for high resolution hydrologic design. Urban Water J., 9(2), 57-65.

Bellu, A., Fernandes, L. F. S., Cortes, R. M., Pacheco, F. A., 2016. A framework model for the dimensioning and allocation of a detention basin system: The case of a flood-prone mountainous watershed. J. Hydrol., 533, 567-580.

Chapman, C., Horner, R. R., 2010. Performance assessment of a street-drainage bioretention system. Water Environ. Res., 82(2), 109-119.

Chen, Y., Samuelson, H. W., Tong, Z., 2016. Integrated design workflow and a new tool for urban rainwater management. J. Environ. Manag., 180, 45-51.

Chow, V.T., Maidment, D. R., Mays, L.W., 1988. Applied hydrology. McGraw-Hill Book Company, Maidenherd. 
Cibin, R., \& Chaubey, I., 2015. A computationally efficient approach for watershed scale spatial optimization. Environ. Modell. Software, 66, 1-11.

Cimorelli, L., Morlando, F., Cozzolino, L., Covelli, C., Della Morte, R., Pianese, D., 2015. Optimal positioning and sizing of detention tanks within urban drainage networks. J. Irrig. Drain. Eng., 142(1), 04015028.

Coleman, T., Branch, M. A., Grace, A., 1999. Optimization toolbox. For Use with MATLAB. User’s Guide for MATLAB 5, Version 2, Relaese II.

Cunha, M. C., Zeferino, J. A., Simões, N. E., Saldarriaga, J. G., 2016. Optimal location and sizing of storage units in a drainage system. Environ. Modell. Software, 83, 155-166.

Deb, K., Pratap, A., Agarwal, S., Meyarivan, T. A. M. T., 2002. A fast and elitist multiobjective genetic algorithm: NSGA-II. IEEE Trans. Evol. Comput., 6(2), 182-197.

De Martino, G., De Paola, F., Fontana, N., Marini, G., Ranucci, A., 2012. Experimental assessment of level pool routing in preliminary design of floodplain storage. Sci. Total Environ., 416, 142-147.

De Paola, F., Ranucci, A., 2012. Analysis of spatial variability for stormwater capture tank assessment. Irrig. Drain., 61(5), 682-690.

De Paola, F., Ranucci, A., Feo, A., 2013. Antecedent moisture condition (SCS) frequency assessment: a case study in southern Italy. Irrig. Drain., 62(S2), 61-71.

Holland, J. H., 1992. Adaptation in natural and artificial systems: an introductory analysis with applications to biology, control, and artificial intelligence. MIT press.

Huang, C. L., Hsu, N. S., Wei, C. C., Luo, W. J., 2015. Optimal spatial design of capacity and quantity of rainwater harvesting systems for urban flood mitigation. Water, Vol. 7, No. 9, pp. 5173-5202. 
James, B., Dovit, A., 1985. Structural optimization by multilevel decomposition.

Kadaba, N., Nygard, K. E., 2014. Improving the performance of genetic algorithms in automated discovery of parameters. In Machine Learning: Proceedings of the Seventh International Conference (pp. 140-148).

Kalcic, M., Prokopy, L., Frankenberger, J., Chaubey, I., 2014. An in-depth examination of farmers’ perceptions of targeting conservation practices. Environ. Manage., 54(4), 795-813.

Kirshen, P., Caputo, L., Vogel, R. M., Mathisen, P., Rosner, A., Renaud, T., 2014. Adapting urban infrastructure to climate change: A drainage case study. J. Water Resour. Plann. Manage., 141(4), 04014064.

Krebs, G., Kokkonen, T., Valtanen, M., Koivusalo, H., Setälä, H., 2013. A high resolution application of a stormwater management model (SWMM) using genetic parameter optimization. Urban Water J., 10(6), 394-410.

Li, F., Duan, H.F., Yan, H.X., Tao T., 2015. Multi-Objective Optimal Design of Detention Tanks in the Urban Stormwater Drainage System: Framework Development and Case Study. Water Resour. Manage., 29(7), 2125 - 2137. https://doi.org/10.1007/s11269-015-0931-0

Lin, C. C., Lee, Y. J., 2004. Stacking sequence optimization of laminated composite structures using genetic algorithm with local improvement. Compos. Struct., 63(3), 339-345.

Lu, W., Qin, X.S., Yu, J.J., 2017a. Emulator-aided optimization of detention tanks for flood reduction, In Proceedings of the 37th IAHR World Congress, Kuala Lumpur, Malaysia, 1318 August, 2017, pp.4165-4170.

Lu, W., Qin, X., Jun, C., 2017b. (In press) A Parsimonious Framework of Evaluating WSUD Features in Urban Flood Mitigation. J. Environ. Inf., 0. Retrieved from http://www.jeionline.org/index.php?journal=mys\&page=article\&op=view\&path\%5B\%5D= 
649 Lucas, J. M., 1976. Which response surface design is best: a performance comparison of several types of quadratic response surface designs in symmetric regions. Technometrics, 18(4),

652 MATLAB, 2015. Global Optimization Toolbox. Use’s Guide (R2015b).

653 McKay, M. D., Beckman, R. J., Conover, W. J., 1979. Comparison of three methods for 654 selecting values of input variables in the analysis of output from a computer code. Technometrics, 21(2), 239-245.

656

657

658

659

660

661

662

663

664

665

666

667 668

669

670

Meteorological Service Singapore., 2017. Climate of Singapore. http://www.weather.gov.sg/climate-climate-of-singapore/ (accessed Nov. 19, 2017)

Oxley, R. L., Mays, L. W., 2014. Optimization-simulation model for detention basin system design. Water Resour. Manage., 28(4), 1157-1171.

Public Utility Board (PUB). 2011. Code of Practice on Surface Water Drainage. (Sixth Edition) https://www.pub.gov.sg/Documents/COP_Final.pdf (accessed Nov. 19, 2017)

Rossman, L. A., 2010. Storm Water Management Model-User manual Version 5.0. Revised July 2010. US Environmental Protection Agency (US EPA), Cincinnati, USA.

Seo, J., Dueñas-Osorio, L., Craig, J. I., Goodno, B. J., 2012. Metamodel-based regional vulnerability estimate of irregular steel moment-frame structures subjected to earthquake events. Eng. Struct., 45, 585-597.

Sreekanth, J., Datta, B., 2011. Comparative evaluation of genetic programming and neural network as potential surrogate models for coastal aquifer management. Water Resour. Manage., 25(13), 3201-3218.

Tao, T., Wang, J., Xin, K., Li, S., 2014. Multi-objective optimal layout of distributed storm- 
water detention. Int. J. Environ. Sci. Technol., 11(5), 1473-1480.

672 Topa, M. E., Giugni, M., De Paola, F., 2014. Off-stream floodplain storage: numerical modeling 673 and experimental analysis. J. Irrig. Drain. Eng., 141(1), 04014040.

674 US Environmental Protection Agency (US EPA), 2017. Storm Water Management Model 675 (SWMM) - Version 5.1.010 with Low Impact Development (LID) Controls.

676 https://www.epa.gov/water-research/storm-water-management-model-swmm (accessed Nov.

$677 \quad 19,2017)$

678 Wang, M., Sun, Y., Sweetapple, C., 2017. Optimization of storage tank locations in an urban 679 stormwater drainage system using a two-stage approach. J. Environ. Manage., 204, 31-38.

680 Yu, J. J., Qin, X. S., Larsen, O., 2015a. Applying ANN emulators in uncertainty assessment of 681 flood inundation modelling: a comparison of two surrogate schemes. Hydrol. Sci. J., 60(12), $682 \quad 2117-2131$.

683 Yu, J. J., Qin, X. S., Larsen, O., 2015b. Uncertainty analysis of flood inundation modelling using 684 GLUE with surrogate models in stochastic sampling. Hydro. Processes, 29(6), 1267-1279. 685 Yu, J., Qin, X., Chiew, Y. M., Min, R., Shen, X., 2017. Stochastic Optimization Model for 686 Supporting Urban Drainage Design under Complexity. J. Water Resour. Plann. Manage., 687 143(9), 05017008.

688 
689 Table Captions:

690 Table 1. Flooding information and allocated storage ponds for sub-watersheds in Scenario I.

691 Table 2. Optimal layout of storage ponds in each sub-watersheds and overall performance of TO

692 scheme under Scenario I.

693 Table 3. Results of two optimization schemes under Scenarios I, IA, IB, II and III.

694 Table 4. Results of GO scheme under different GA options.

695 
Table 1. Flooding information and allocated storage ponds for sub-watersheds in Scenario I.

697

\begin{tabular}{ccccc}
\hline $\begin{array}{c}\text { Sub-watershed } \\
\text { No. } \\
\left(S_{i}\right)\end{array}$ & $\begin{array}{c}\text { Flood volume } \\
\left(10^{3} \mathrm{~m}^{3}\right)\end{array}$ & $\begin{array}{c}\text { Flood } \\
\text { percentage } \\
(\%)\end{array}$ & $\begin{array}{c}\text { Number of } \\
\text { allocated ponds } \\
\left(p_{i}\right)\end{array}$ & $\begin{array}{c}\text { Number of } \\
\text { original } \\
\text { junctions }\end{array}$ \\
\hline$S_{1}$ & 192.5 & 27.6 & 11 & 20 \\
\hline$S_{2}$ & 155.3 & 22.2 & 10 & 21 \\
\hline$S_{3}$ & 181.1 & 26.0 & 11 & 20 \\
\hline$S_{4}$ & 169.0 & 24.2 & 10 & 20 \\
\hline Sum & 697.9 & 100 & 42 & 81 \\
\hline
\end{tabular}

698

699 
700

701

702

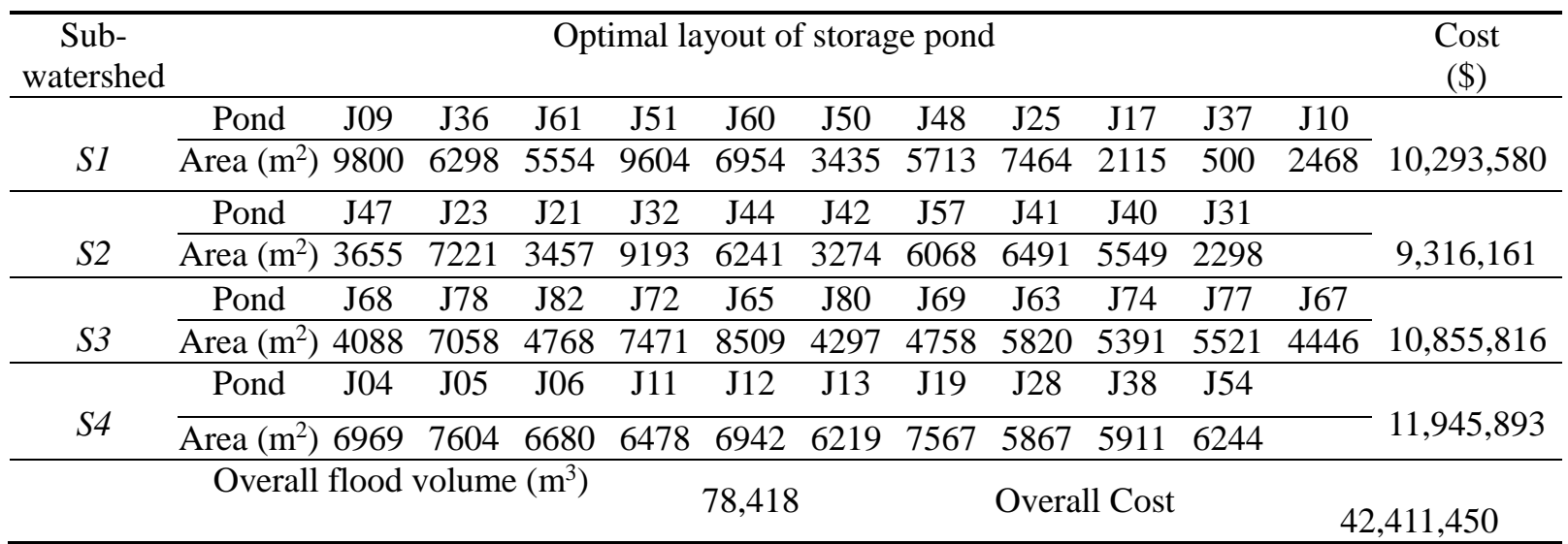
scheme under Scenario I.

Table 2. Optimal layout of storage ponds in each sub-watersheds and overall performance of TO 


\begin{tabular}{|c|c|c|c|c|c|c|c|c|c|c|c|c|}
\hline \multirow[t]{2}{*}{ Scenarios } & \multicolumn{5}{|c|}{$\begin{array}{l}\text { Optimized number of } \\
\text { ponds: TO }\end{array}$} & \multirow{2}{*}{$\begin{array}{l}\text { Optimized } \\
\text { number of } \\
\text { ponds: GO }\end{array}$} & \multicolumn{2}{|c|}{$\begin{array}{l}\text { Overall cost } \\
(\$)\end{array}$} & \multicolumn{2}{|c|}{$\begin{array}{l}\text { Total flood volume } \\
\left(\mathrm{m}^{3}\right)\end{array}$} & \multicolumn{2}{|c|}{$\begin{array}{l}\text { Total run } \\
\text { time (hour) }\end{array}$} \\
\hline & S1 & $S 2$ & S3 & S4 & $\overline{\text { Sum }}$ & & TO & GO & TO & GO & TO & GO \\
\hline I & 11 & 10 & 11 & 10 & 42 & & $42,411,450$ & & 78,418 & & & \\
\hline IA & 12 & 10 & 10 & 17 & 49 & 71 & $50,335,665$ & $48,090,220$ & 79,483 & 79,934 & 3.3 & 6.5 \\
\hline IB & 11 & 8 & 15 & 9 & 43 & & $43,456,687$ & & 79,366 & & & \\
\hline II & 9 & 9 & 9 & 11 & 38 & 66 & $38,866,884$ & $43,252,806$ & 117,866 & 111,278 & & \\
\hline III & 13 & 11 & 13 & 12 & 49 & 74 & $48,108,047$ & $52,684,022$ & 59,283 & 58,422 & & \\
\hline
\end{tabular}


709

\begin{tabular}{ccccc}
\hline \multirow{2}{*}{ No. of run } & \multicolumn{2}{c}{ Options of GA } & \multicolumn{2}{c}{ Results of GO } \\
\cline { 2 - 5 } & Elite count & $\begin{array}{c}\text { Crossover } \\
\text { fraction }\end{array}$ & $\begin{array}{c}\text { Overall cost } \\
(\$)\end{array}$ & $\begin{array}{c}\text { Total flood } \\
\text { volume }\left(\mathrm{m}^{3}\right)\end{array}$ \\
\hline 1 & 3 & 0.6 & $49,763,148$ & 79,392 \\
\hline 2 & 6 & 0.7 & $46,628,648$ & 79,991 \\
\hline 3 & 10 & 0.8 & $48,090,220$ & 79,934 \\
\hline 4 & 15 & 0.85 & $46,795,460$ & 79,984 \\
\hline
\end{tabular}

710

711 


\section{$712 \quad$ Figure Captions:}

713 Figure 1. Flow diagram of the proposed design framework.

714 Figure 2. Layout of the studied drainage network and model setting.

715 Figure 3. Hyetograph of the design rainfall.

716 Figure 4. Division of sub-watersheds over the study domain.

717 Figure 5. Regression performance of quadratic surrogate model for tributary sub-watersheds S1

718 to $S 4$.

719 Figure 6. Results based on Scenario III with different SPs for (a) optimized pond areas and costs

720 of each sub-watershed from TO scheme and (b) optimized pond areas and final costs from GO

721 scheme.

722 Figure 7. Sample scenarios of flood volumes at tributary sub-watersheds (S1, S2 and S3) and 723 mainstream sub-watershed S4.

724 Figure 8. Flood volumes at various junctions (with a threshold of $500 \mathrm{~m}^{3}$ ) from two optimal 725 solutions (i.e. original Scenario I model and the model with Extra-con on controlling backflow 726 effect) under TO scheme.

727 Figure 9. The new division of sub-watersheds over the study domain for Scenario IB. 


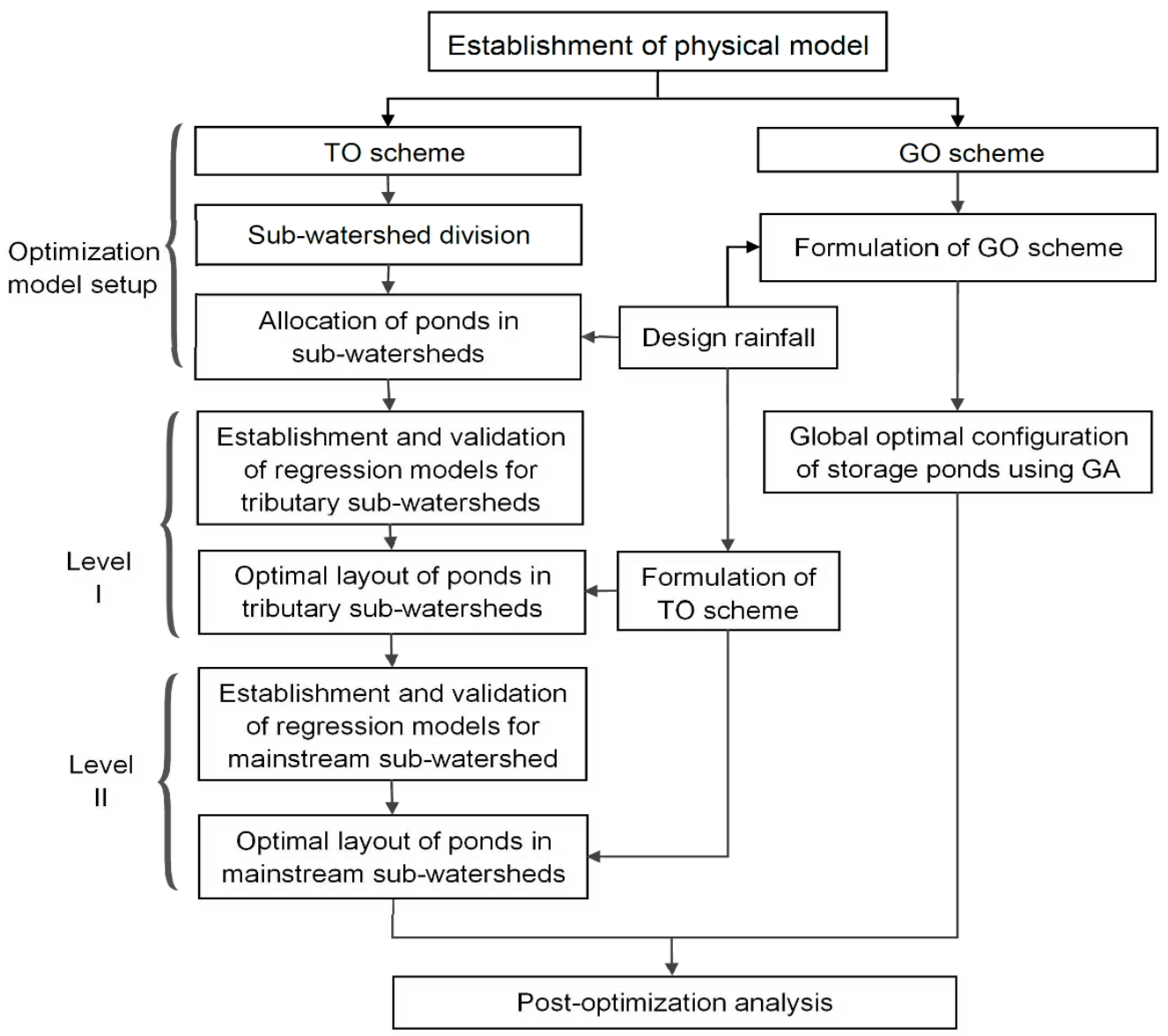

729

Figure 1. Flow diagram of the proposed design framework. 


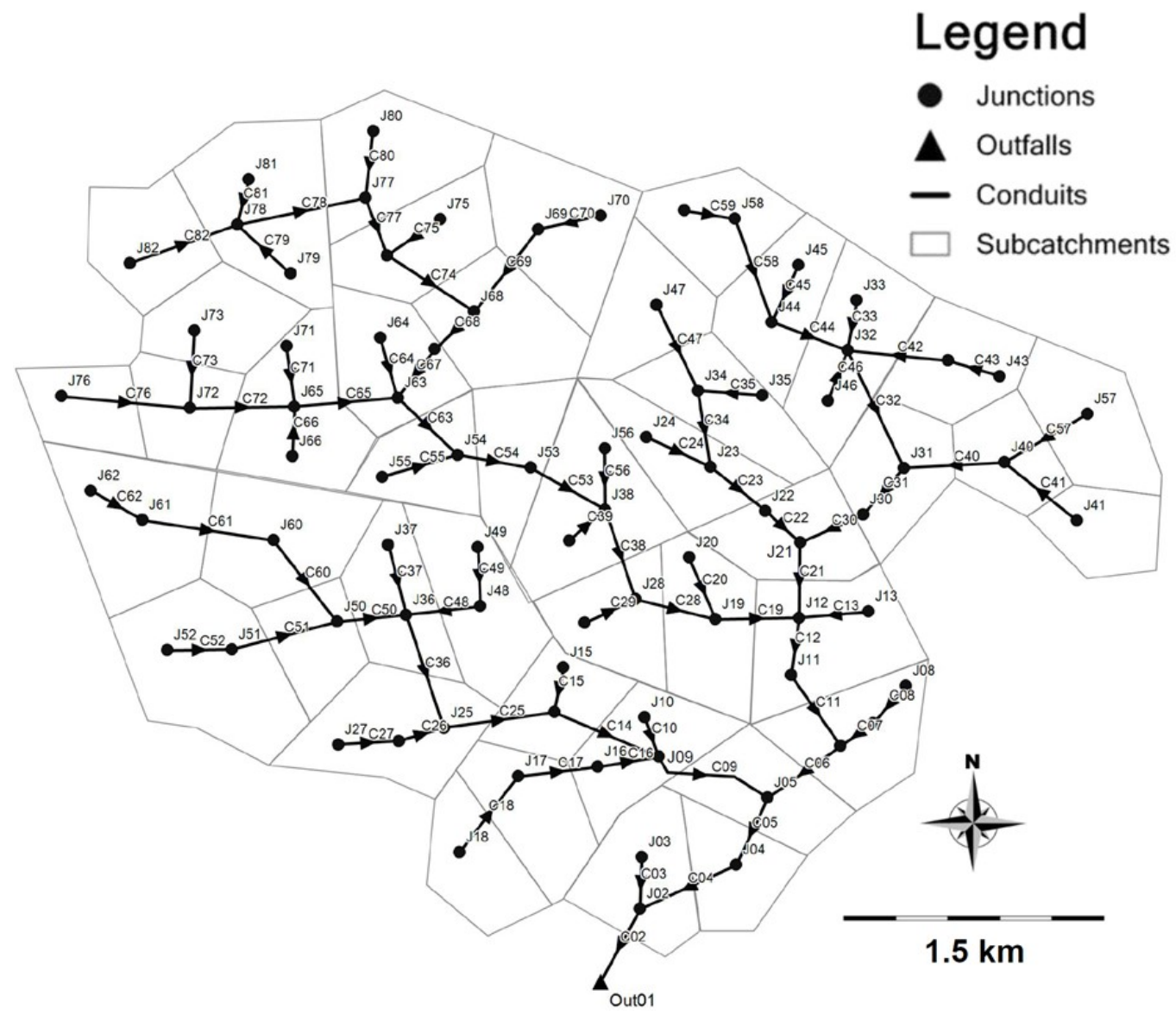

Figure 2. Layout of the studied drainage network and model setting. 


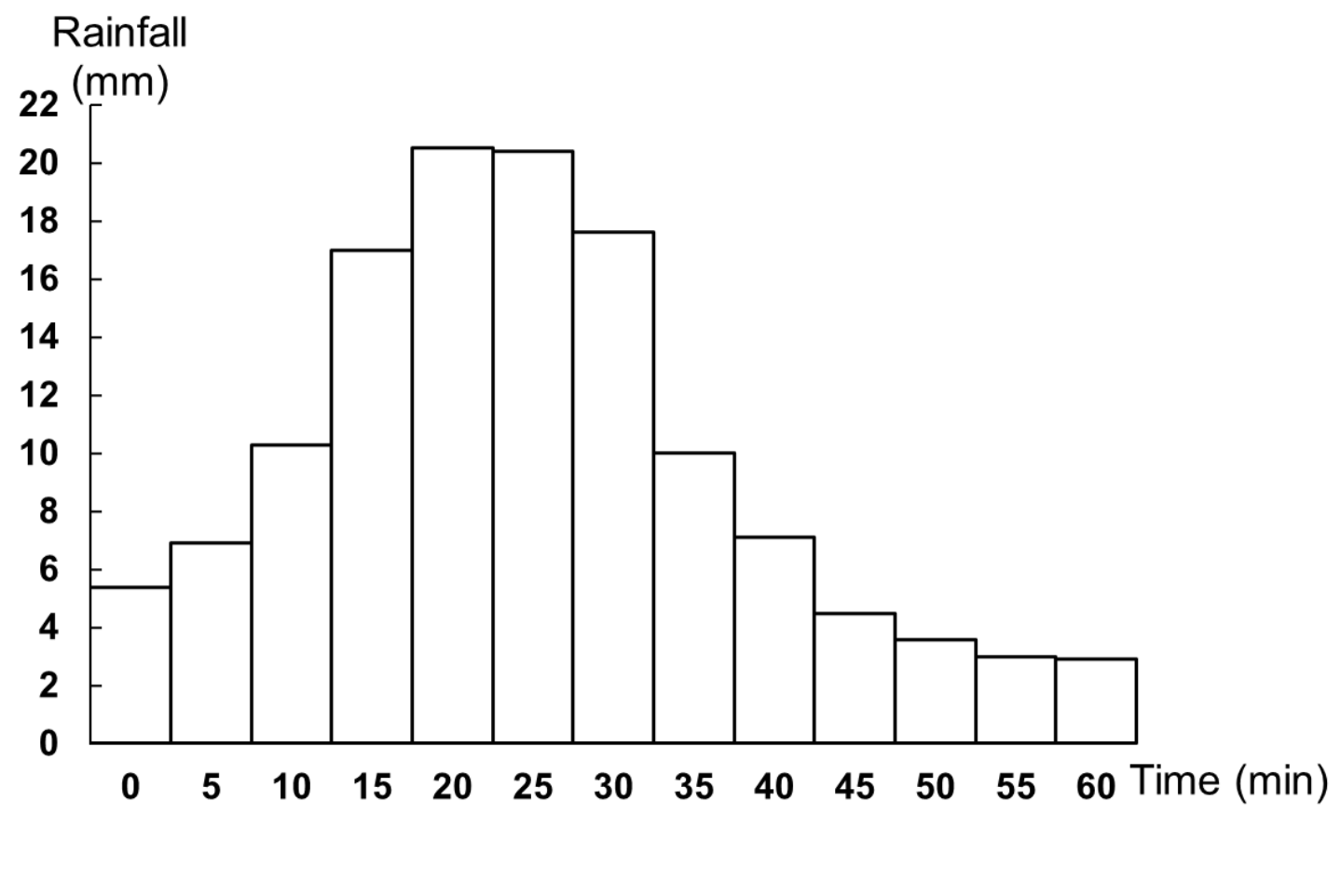

Figure 3. Hyetograph of the design rainfall 


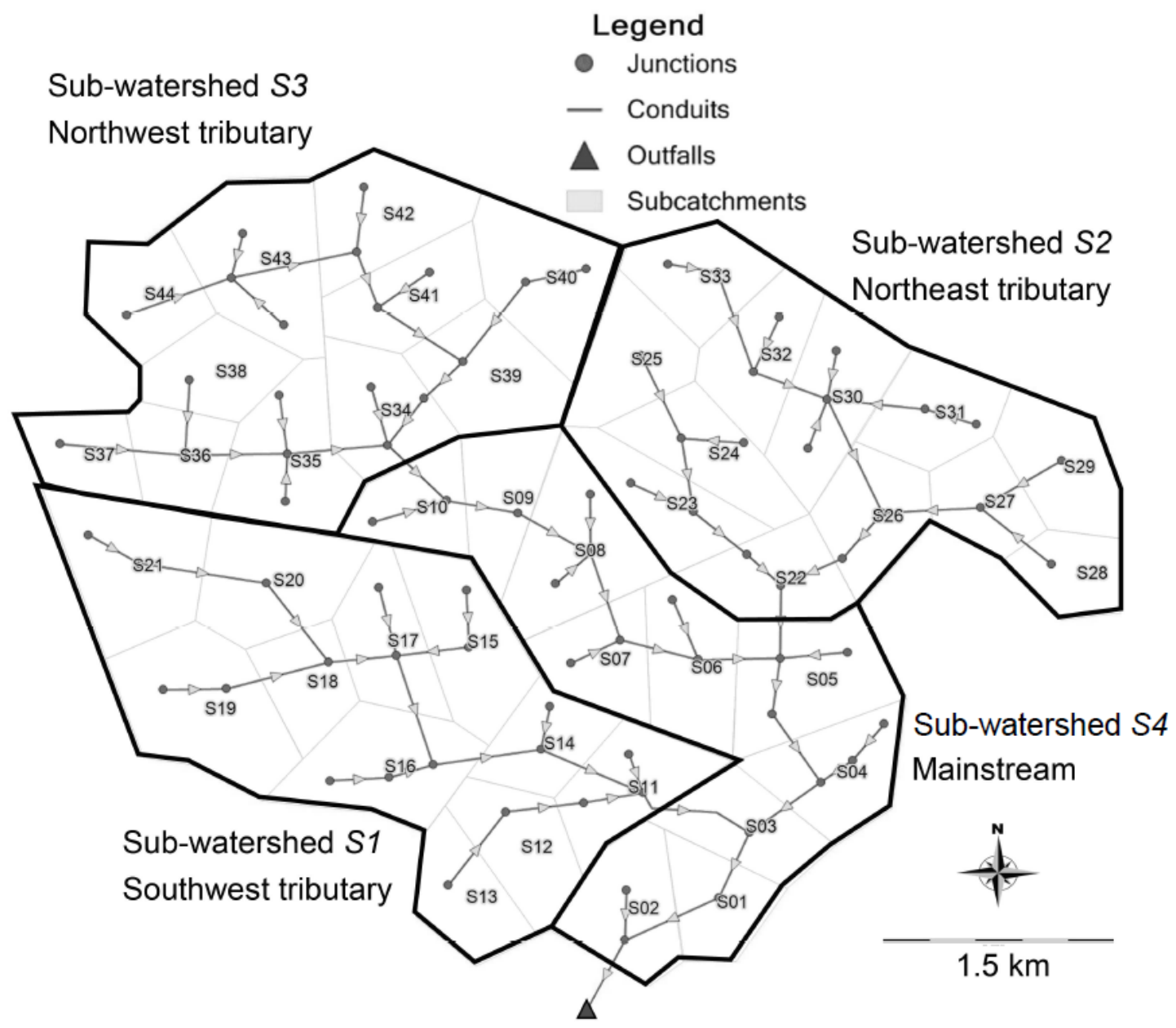

Figure 4. Division of sub-watersheds over the study domain. 


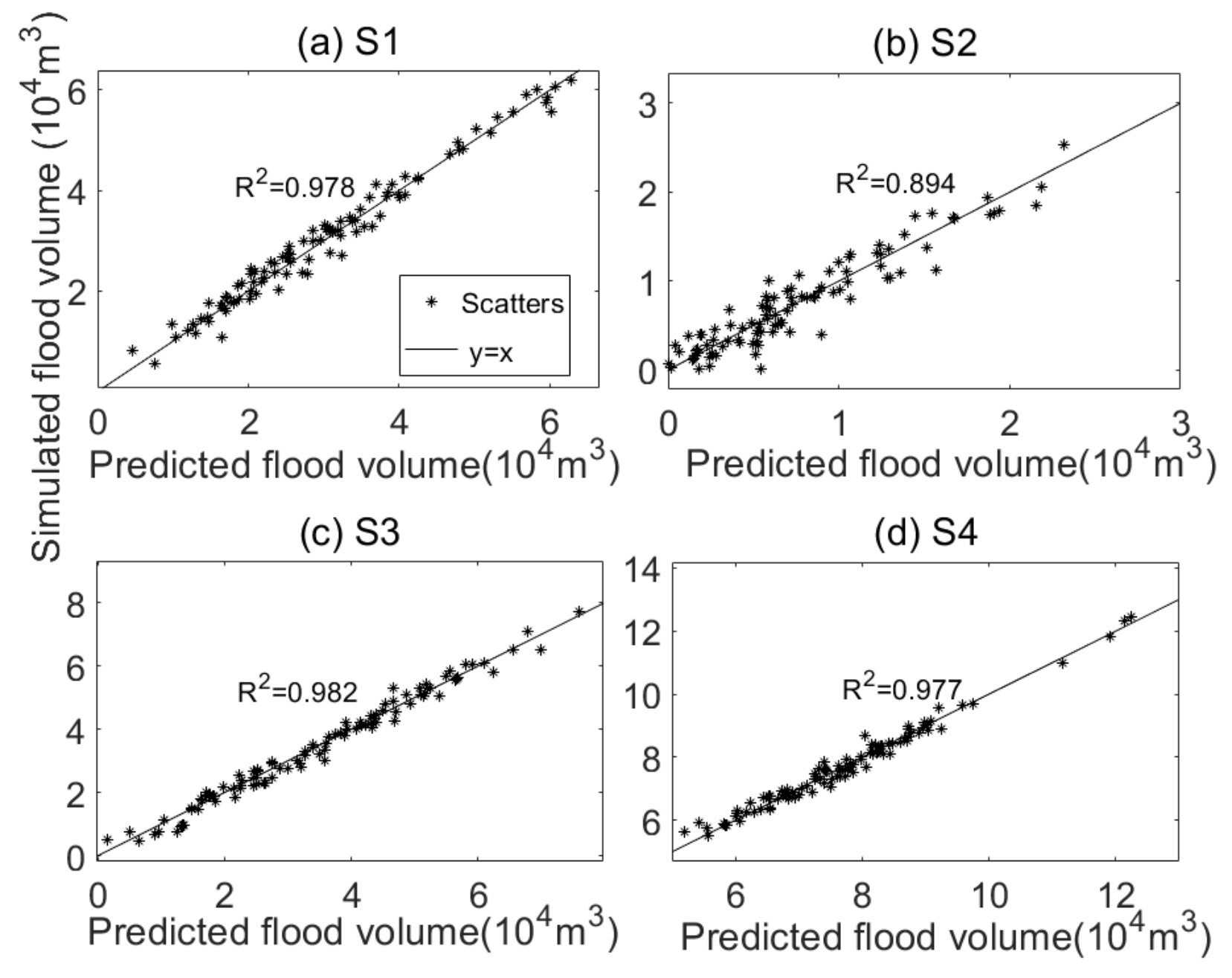

747 Figure 5. Regression performance of quadratic surrogate model for tributary sub-watersheds S1 to $S 4$. 

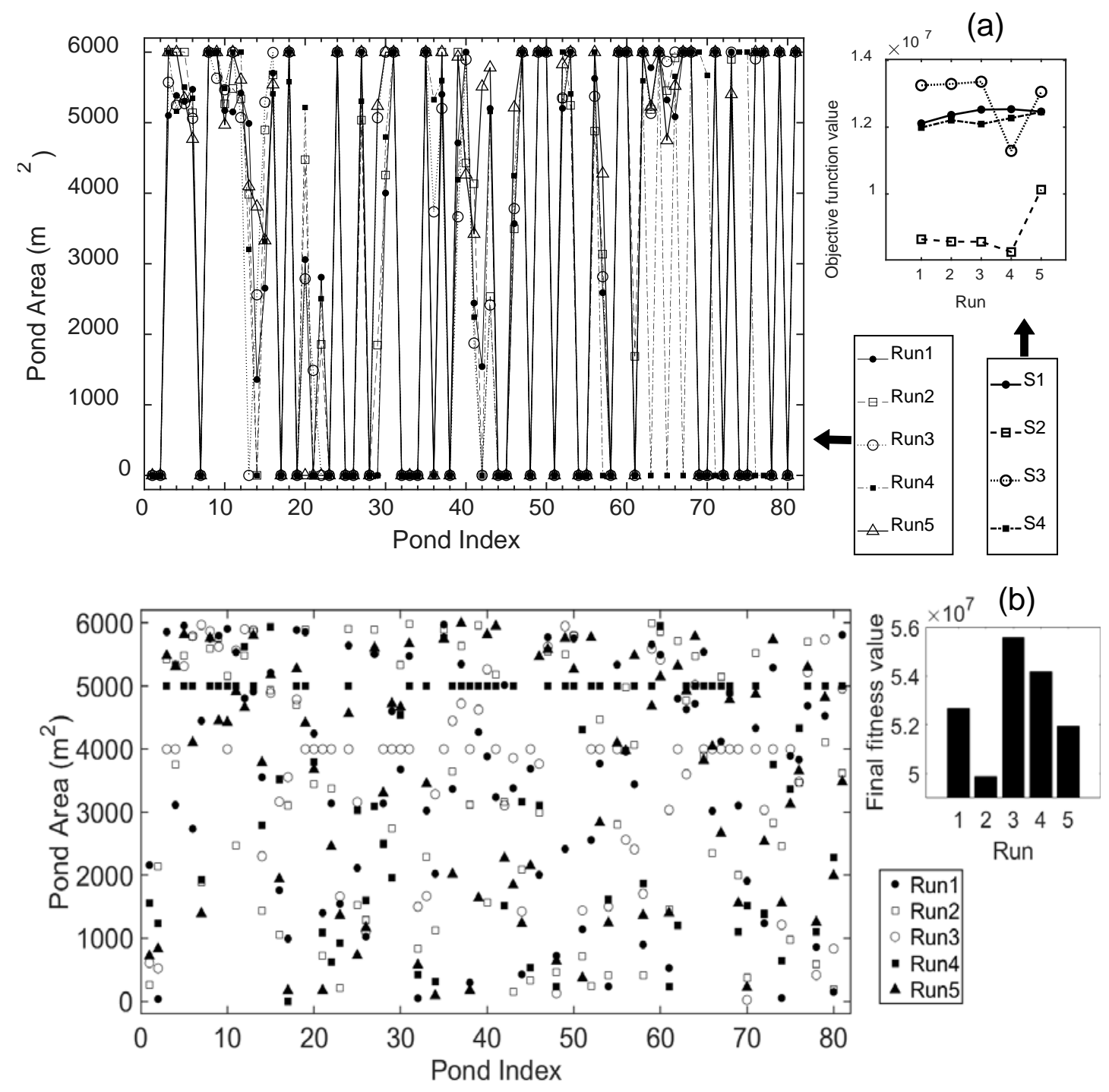

752 Figure 6. Results based on Scenario III with different SPs for (a) optimized pond areas and costs 753 of each sub-watershed from TO scheme and (b) optimized pond areas and final costs from GO scheme. 


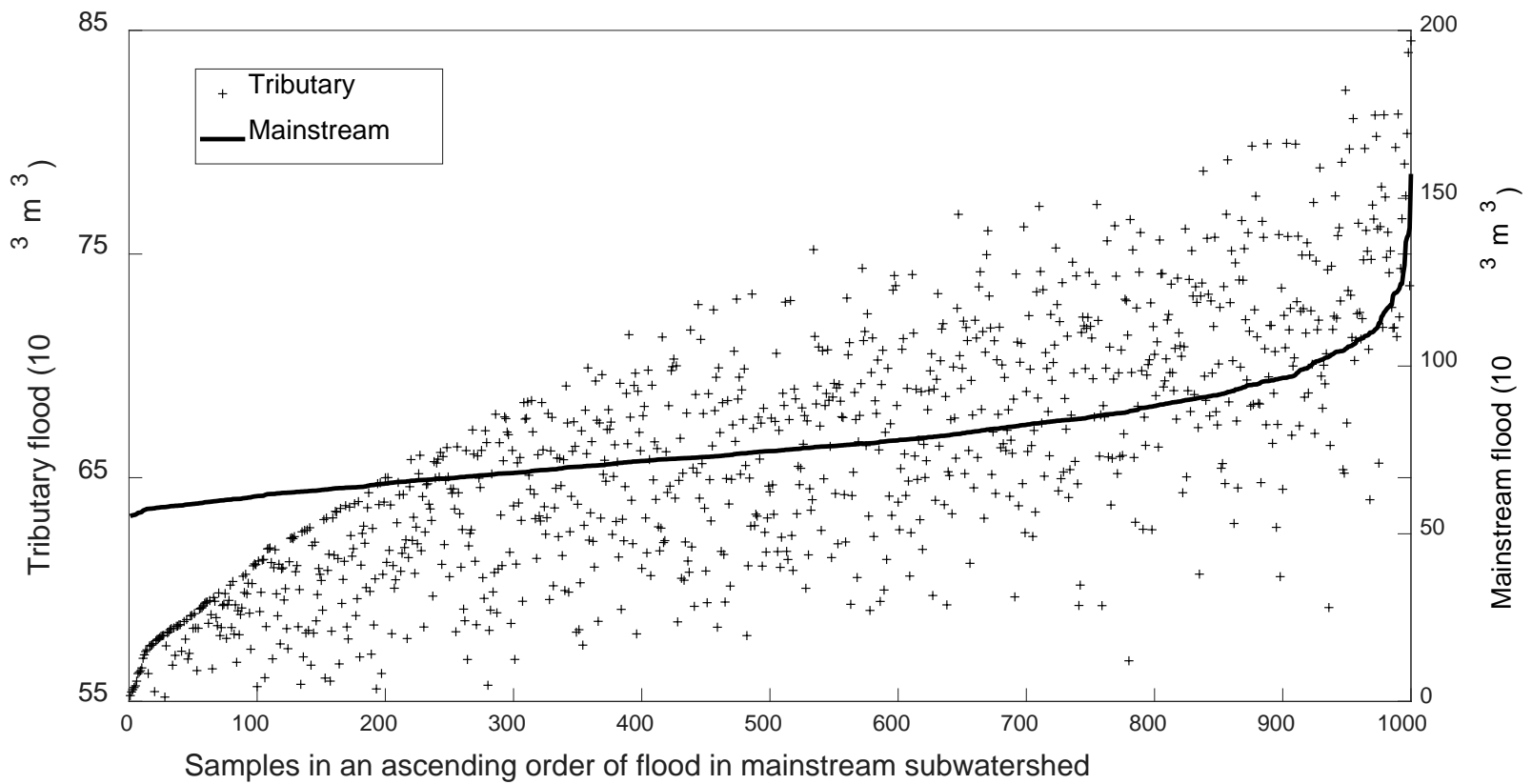

Figure 7. Sample scenarios of total flood volumes at tributary sub-watersheds ( $S 1, S 2$ and $S 3$ ) and mainstream sub-watershed $S 4$.

760 


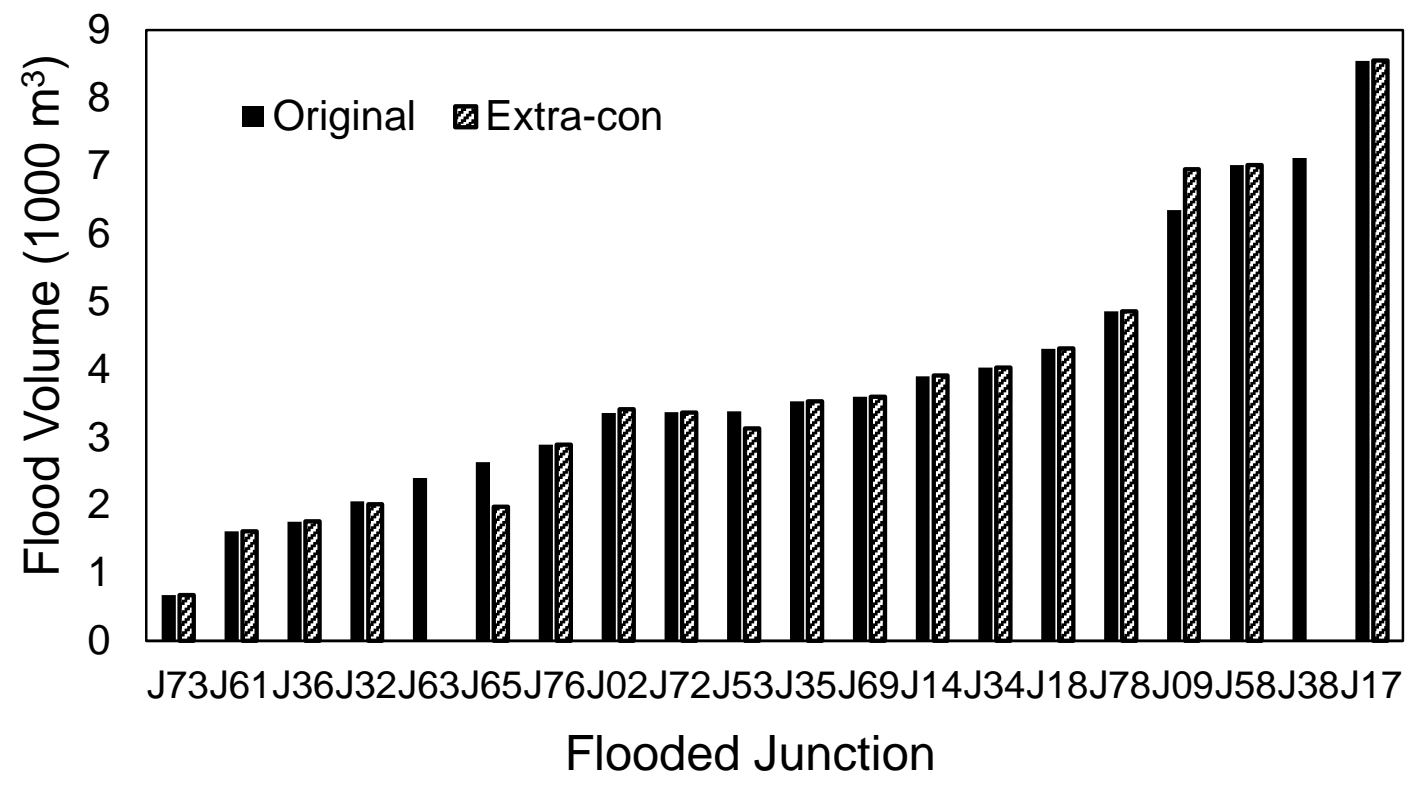

762

763

764 Figure 8. Flood volume at various junctions (with a threshold of $500 \mathrm{~m}^{3}$ ) from two optimal 765 solutions (i.e. original Scenario I model and the model with Extra-con on controlling backflow 766 effect) under the TO scheme.

767 


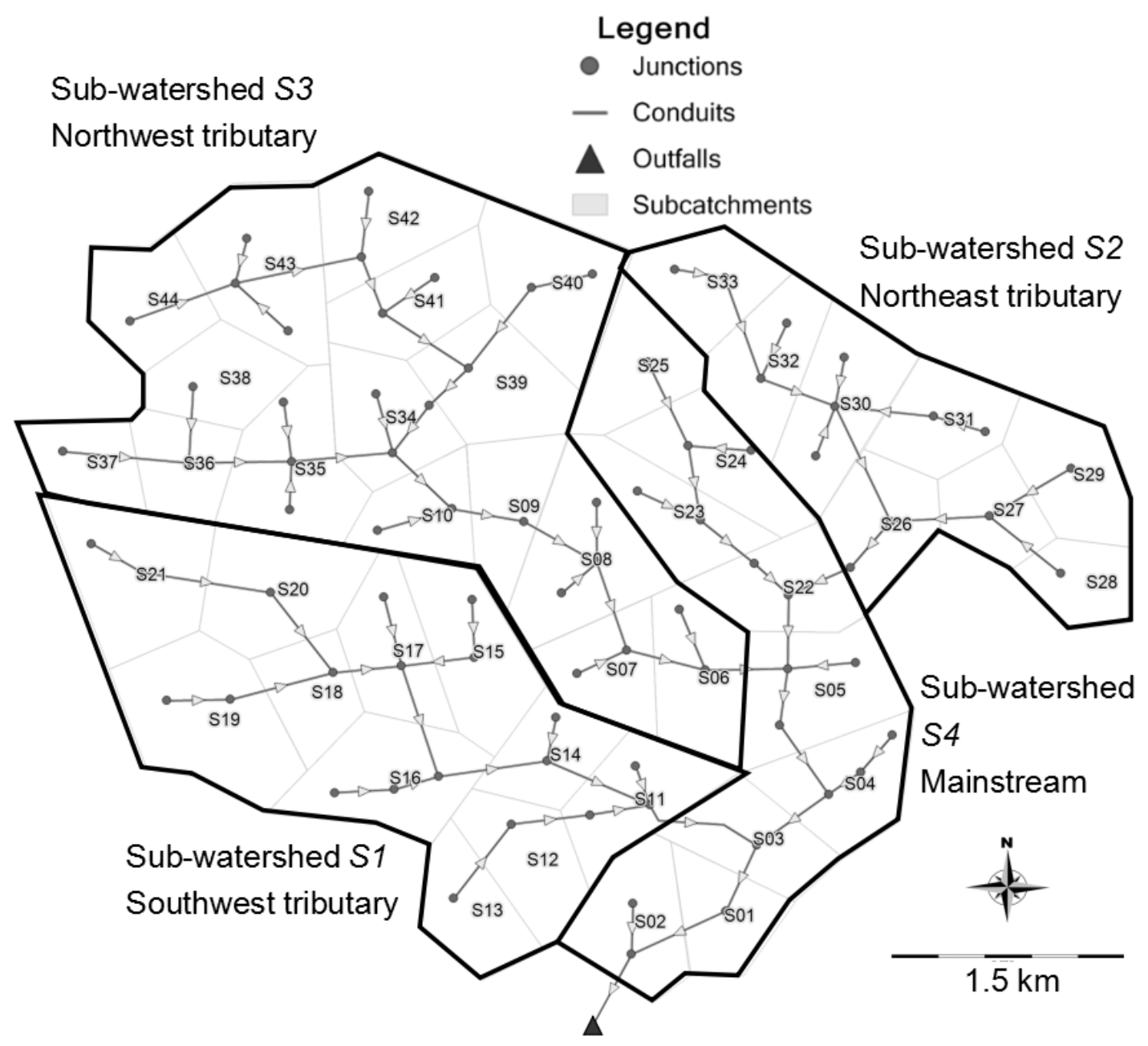

Figure 9. The new division of sub-watersheds over the study domain for Scenario IB. 